\title{
Trichodental syndrome
}

\author{
INSERM
}

\section{Source}

INSERM. (1999). Orphanet: an online rare disease and orphan drug data base.

Trichodental syndrome. ORPHA:3351

Trichodental syndrome is characterised by the association of fine, dry and short hair with dental anomalies. It has been described in less than 10 families. The mode of transmission is autosomal dominant. 